\title{
Engineering \\ Investigating the Cooling Performance of Vehicle Engines Using Radiator with Nano-fluid as A Coolant
}

\author{
Farag, A. ${ }^{1^{*}}$, Nabil, T. $^{2}$, Elfarran, M. ${ }^{1}$ \\ ${ }^{1}$ Aeronautical Engineering Department, Institute of Aviation Engineering and Technology, Giza, Egypt \\ ${ }^{2}$ Mechanical Engineering Department, Faculty of Engineering, Suez Canal University, Ismailia, Egypt \\ *Corresponding author e-mail: ahmedmfarag1978@gmail.com
}

\section{Article Info \\ Received 26 Dec. 2020 \\ Revised 4 Dec. 2021 \\ Accepted 14 Jan. 2022}

\section{Keywords}

Nano-fluid; coolant; Nanoparticles; vehicle; engine; frontal; cooling.

\begin{abstract}
In the cooling system of the automobile engine, the water which is used as a coolant is evaporated due to high engine temperature, so it is needed to add some additives to the coolant water but it does not give it high performance compared to adding some of Nano-particles. This work aims to do an investigation in heat transfer characteristics with Nano-fluid, which has revealed that when Nano-particles are introduced to a conventional fluid in certain concentrations they enhance the ability to transfer heat, has the benefits of lower energy costs and the environmental impact. This enhancement leads to reduce the radiator frontal area which results in reducing the frontal area of the vehicle that leads to lowering the coefficient of drag (resistance of the air for the moving vehicle) consequently reduces the fuel consumption. Two types of Nano particles metal ( $\mathrm{Cu}$ ) and metal oxide ( $\mathrm{CuO}$ ) are used to prepare coolant Nano-fluids with different concentrations. Also, the pump characteristics using Nano-fluid as a fluid are investigated.
\end{abstract}

\section{Introduction}

Cooling system of the vehicle classified into two types: air and water cooling system. Air cooling systems are suitable for small engines which generates about $15-20 \mathrm{KW}$ or aero plane engines. Water cooling system using water jackets around the engine to absorb the heat generated inside the cylinders then cooling it down. Water cooling system components are; Radiator, Thermostat valve, Water pump, Fan, Water jacket and Antifreeze mixture. For metallurgical issues it is impossible to let the temperature of automobile engines to increase without cooling which may cause series damage inside the engine parts. A lot of ideas were pronounced in this field; it was taken to a high level of developing the coolant itself. Using Nano-fluid was a great idea of them; Nano-particles mixed with car coolant gives new thermal properties with good thermo-physical properties like conductivity, viscosity, density and specific heat which leads to a better coolant. Think of it as a series, better cooling, smaller radiator size, smaller frontal area, lower air resistance, lower drag, lower fuel consumption, lower exhaust gases, high performance of the vehicle. Nanaware and Hole [1] investigated the Nano-fluid which can be used as cooling technique for enhancement heat transfer rate of vehicle engine.

Kamel, et al. [2] found that; the Reynolds number of Nano-fluid is directly proportional to Heat transfer, increasing volume or mass Concentration of Nano- particles will increase the pressure drop of Nano-fluid $s$, most effective shape is spherical shape of particles, the heat transfer rate increases by fine grade of Nanoparticles but poor stability will be a problem. Vafai and Khanate [3] showed the experimental and theoretical analysis of viscosity and thermal conductivity reported by several authors. They found that viscosity increase with increasing volume fraction and decrease with increasing temperature and found that Thermal conductivity increase with increasing volume fraction and decrease with increasing the particle diameter.

Ghosh et al. [4] found that the Nano-fluids properties depend on the thermal conductivity, elastic modulus, density and Poisson's ratio of the Nanoparticle. They have made the simulation for thermal conductivity of Nano-fluid by MD-stochastic model. Alpesh Mehta et al [5] investigated the Nanofluid used in heat exchanger. They are using $\mathrm{Al} 2 \mathrm{O} 3$ as a Nano-fluid. They used radiator with unmixed fluids consisting of 644 tubes made of brass and 346 continuous fins made of copper. A.R. Solankee and Prof.S.R. Kulkarni [6] have made a review on Nanoparticles like titanium, aluminum, copper, Iron, silver and uses many base fluids. Applications use this type of Nano-fluid are application for lubrication, Refrigeration, coating, automobile, machining of various materials, heat transfer and electronics.

Elumagandla Surendar et al [7] used $\mathrm{Al} 2 \mathrm{O} 3$ as a Nano-particles in different volume concentrations $(0.03,0.054,0.067$ and 0.135$) \%$ flowing as turbulent flow conditions. They investigated that analytical 
calculations on heat exchanger, flow characteristics and forced convective heat transfer of a Nano-fluid. The thermal analysis and CFD made using ANSYS fluent.

Kaufui V.Wong and Michael J. Castillo [8] discussed the effect of clustering on thermal conductivity it shows the relationship between thermal conductivity and other factors like particle size, temperature and concentration. Ramin Ranjbarzadeh et al. [9] aimed to increase heat transfer rate in order to increase thermal efficiency which lead to reducing fuel consumption and air pollution. A Nano-particles of silica with water as a base fluid was used. Stability was measured and indicated a high stability for long period of time even after 6 months. Thermal conductivity was found the best at volume fraction of $3 \% @ 55^{\circ} \mathrm{C}$, with improvement of $33 \%$ of thermal conductivity.

Wei $\mathrm{Yu}$ and Huaqing Xie [10], Studied the development of Nano-fluid $s$ including different methods of preparation, enhancing the stability, various applications of heat transfer, enhancement of heat transfer, mechanical and biomedical fields. Roshan V. Marode et al. [11] collected many reviews of heat exchanger performance using different types of Nano-particles like $\mathrm{Al2O} 3, \mathrm{TiO} 2, \mathrm{SiO} 2$ and calculated its different properties.

Hanif et al. [12] studied the enhancement of thermal conductivity and dynamic viscosity of Nanofluids. They established that by using the Nano-fluid the shape of the car and its weight could be modified into something better to save fuel.

\section{Fabrication technique of nano-particles}

The Nano particles prepared by two step method, this method is better for preparing Nano-fluid as it gives a high control of particle size and its suspension in the fluid. It's mainly used for scientific research purposes the Nanoparticles in this method is mixed with the base fluid by either a chemical or physical methods (the evaporation and inert gas condensation process) then it's mixed by the ultra-sonication devices to get more and more stable mixture. The Nanoparticles may agglomerate in the base fluid if it was not processed well (adding sufficient amount of stabilizer).

Copper Nano-particles was prepared using Sonochemical method. Copper Nano-particles was reduced by Ascorbic Acid, $1.5 \mathrm{~g}$ of $\mathrm{CuSO} 4$ dissolved into $50 \mathrm{ml}$ of doubled deionized water and $3 \mathrm{~g}$ of Ascorbic Acid dissolved in $50 \mathrm{ml}$ of doubled deionized water prepared in two different beakers then put CuSO4 beaker on ultrasonic prop device at condition of 0.6. cycle and amplitude $80 \%$ and drop by drop add Ascorbic Acid. The color of mixture become light green and become darker with add Ascorbic Acid then finally rose powder formed of Copper Nanoparticles. Washing several times using Absolut methanol (99.9\%) to prevent oxidation of Copper Nanoparticles. Repeating the process of washing the powder and drying it to ensure that there is no impurities or contaminants in the powder.

Nano copper oxide could be obtained using many ways like sonochemical, thermal oxidation, combustion and quick precipitation but the most used method is the last one as it suits the high production rates and cost efficiency goals and we will discuss it in some manner of details.

Nano copper oxide is prepared using precipitation method from copper nitrate $\left(\mathrm{Cu}\left(\mathrm{NO}_{3}\right) 2.3 \mathrm{H} 2 \mathrm{O}\right)$ and copper chloride $(\mathrm{CuCl} 2)$. firstly, each chemical compound is dissolved in de-ionized water to form a water solution of certain concentration $(0.1 \mathrm{~m})$ then a sodium hydroxide solution of the same concentrations is dropped slowly under stirring till the total solution $\mathrm{PH}$ number be 14 and you notice a black precipitate then wash it with pure ethanol and deionized water till $\mathrm{PH}$ of 7 then, the washed powder is dried at 80 degrees Celsius for about 16 hours. Then the precursors are calcined for four hours at 500 degrees Celsius as shown in figure 1.

Finally, the Nano copper fluid is obtained by mixing the Nano copper oxide powder with the base fluid and stirring the mixture for a proper period in the presence of ultrasonic waves and even without.

Chemical stabilizers also added not to allow the Nano particles to agglomerate like sodium citrate dehydrate in our case.

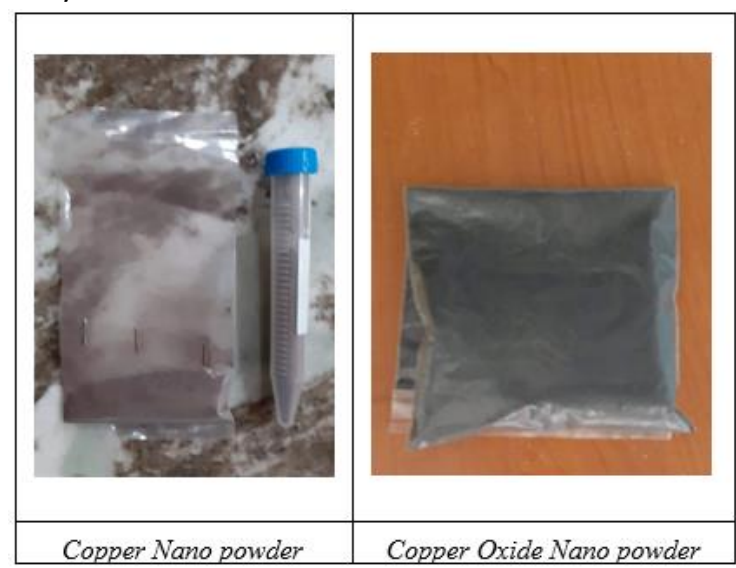

Figure 1 Copper \& Copper Oxide Nano powder.

\section{Nano-Fluid Tests:}

After knowing how the Nano-particles were prepared, this part will introduce the devices that used to detect the crystal structure and optical properties of Nano-particles like Scanning Electron Microscope, Spectroscopic Measurements (X-ray), High Resolution Transmission Electron Microscopy (HRTEM), Field Emission Scanning Electron Microscope (FESEM) and measurement of stability using Zeta potential approach. Let's take these in a little more details.

\section{Scanning Electron Microscope (SEM)}

Electrons are launched from the top of the instrument, accelerated down and passed through a many lenses and apertures to produce group of focused beam of electrons which touches the surface of the sample. The sample is mounted on a stage in the chamber area and, unless the microscope is operated at low vacuums, both the column and the chamber are evacuated by many pumps. We can control vacuum will depend on the design of the microscope. The position of the electron beam on the 
sample we can control by scan coils which situated above the objective lens. These coils allow the beam to be scanned over the surface of the sample. This beam rastering or scanning, as the name of the microscope suggests, enables information about a defined area on the sample to be collected. As a result of the electron-sample interaction, a number of signals are produced. These signals are then detected by appropriate detectors.

\section{High-resolution transmission electron micro-scopy (HRTEM)}

TEM works by using a tungsten coil to produce an electron beam in evacuated chamber. Emission of electrons are accelerated through an electromagnetic field that also narrowly focuses the beam. The beam is then passed through the sample material. The specially prepared sample is a very thin (less than $100 \mathrm{~nm}$ ) slice of material. The electrons that pass through the sample hit a phosphor screen, CCD or film and produce an image. Where the sample has less density, more electrons get through and the image is brighter. A darker image is produced in areas where the sample is denser and therefore less electrons pass through.

\section{Zeta-Sizer}

It's used to measure stability of Nano-particles. Simply stability can be defined as the indication of how long the Nanoparticles will be suspended in fluid without any sedimentation. ZS is a high performance two angle particle and molecular size analyzer for the enhanced detection of aggregates and measurement of small or dilute samples, and samples at very low or high concentration using dynamic light scattering with 'NIBS' optics.

The ZSP also incorporates a zeta potential analyzer that uses electrophoretic light scattering for particles, molecules and surfaces, and a molecular weight analyzer using static light scattering. Using NonInvasive Backscatter optics (NIBS) it has significantly better performance than systems using 90 degree scattering optics. In addition, a micro rheology option is available for measuring sample viscosity and viscoelastic properties, as well as a Protein Measurement option for protein mobility measurements. The flow mode option enables the system to be connected to an SEC or an FFF system to use as a detector for the size of proteins or Nanoparticles. A choice of cuvettes is available, from disposable single-use to specific cells for viscous or high concentration samples or measuring the zeta potential of surfaces.

\section{Devices of preparation}

\section{Spinning disk reactor (SDR)}

It uses the centrifugal force to rotate a $100 \mathrm{~mm}$ diameter disk at speed nearly 600- $1200 \mathrm{rpm}$ and also the desk is heated to $150^{\circ} \mathrm{C}$ allowing mass and heat transfer at higher rates.

Rotating packed-bed reactor (RPBD):
This device is suitable for quick results as it uses the high gravity field energy. The same as the SDR device the liquid enters from the rotor eye outward at speeds of 500- $1000 \mathrm{rpm}$ the liquid drains from inside outside and the gas passes from outside inside to make sure of liquid draining. This device was the one that we used in our preparation of Nano-particles.

\section{Experimental Work:}

There are a lot of experiments had been done to determine engine characteristics that helped to determine radiator size according to engine load. For the radiator itself performance is calculated at different air velocities and varies mass flow rate through radiator fins. A percentage of $33 \%$ of engine power is dissipated by heat transfer through radiator. On the other hand, insufficient heat dissipation can lead to engine over heat which can surly causes the engine to break down. Cooling systems are also used to decrease thermal stresses on the engine, nowadays world tends to redesign the radiators to be more compact while still having the same amount of heat transferred which enhances the aerodynamic of the vehicle which leads better performance and less fuel used.

\section{Cooling system}

Cooling system as was referred earlier one of the most important systems in the vehicles that could be shown schematically by the figure2, it's simply consists of radiator, thermo-couple, pump, fan, flow meter. We made a small model nearly simulating what happens in the car cooling system with some of components as following. (Radiator, Pump, Flow meter, Temperature Sensor, Valve, Hoses, Fan, Pressure gauge, Heater, and Battery).

\section{Experiment setup}

The tank is connected to the water pump through pipes, after the pump, there is a valve to control the mass flow rate and a flow meter to measure flow rate. Then pressure gauge to measure the pressure before the radiator and there is a temperature sensor before radiator to measure temperature at the inlet of radiator. Also, there is a temperature sensor after the radiator to measure temperature at exit of the radiator and a pressure gauge to measure the pressure at exit of radiator, then flow is back to the tank again. Heater is installed into the radiator heating up the fluid. The fan is mounted on the radiator to cool the radiator.

\section{Experiment procedures}

At the beginning of the experiment, we determined a certain volume of fluid to be used with water, coolant and Nano-fluid in all concentrations

- Then we determined a flow rate of all fluids, when valve gate is fully opened (90 degree), semi open to (45 degrees), less opened to 30 degrees.

- Put the fluid in the tank with the heater and turn heater on, then put the tank thermocouple adjusted to $(90-80-70)$ degrees Celsius. 
- When temperature reaches to (90-80-70) degrees Celsius in the tank, pump will turn on automatically by using control system attached to the sensor in the tank.

- The pump draws water from the tank and then delivers it to the radiator.

- Measuring the temperature at radiator inlet and when the temperature is above 60 degrees Celsius the fan automatically opens.

- Fluid passes through radiator for cooling.

- Measuring the temperature at exit of radiator.

- The fluid moves to the reservoir again.

- Repeat the previous steps with different fluids

- Water

- Coolant

- Coolant + Cu 4\% Volume

- Coolant + Cu 2\% Volume

- Coolant + Cu 1\% Volume

- Coolant + CuO 2\% Volume

- Coolant + CuO 1\% Volume

- Repeat the previous steps with the same fluid at different air temperature

- Summer atmosphere

- Temperature: 35-38 degree Celsius

- Humidity: $50-55 \%$

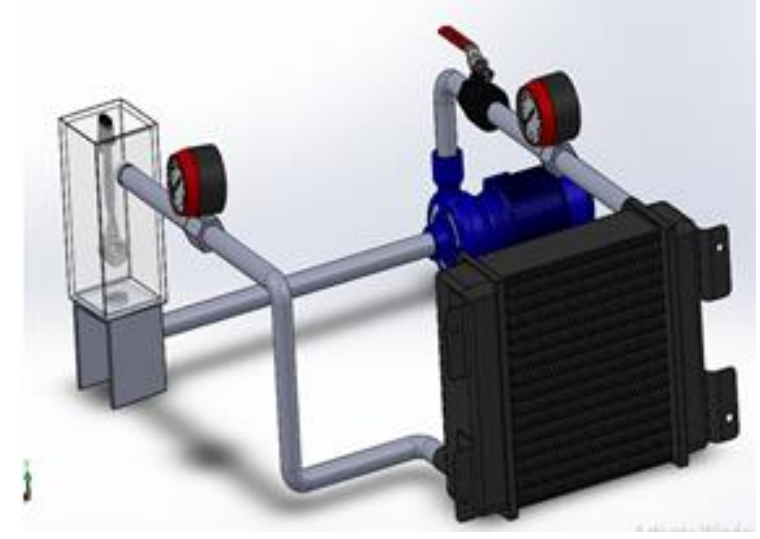

- Winter atmosphere

- Temperature: 20-23 degree Celsius

- Humidity: $30-35 \%$

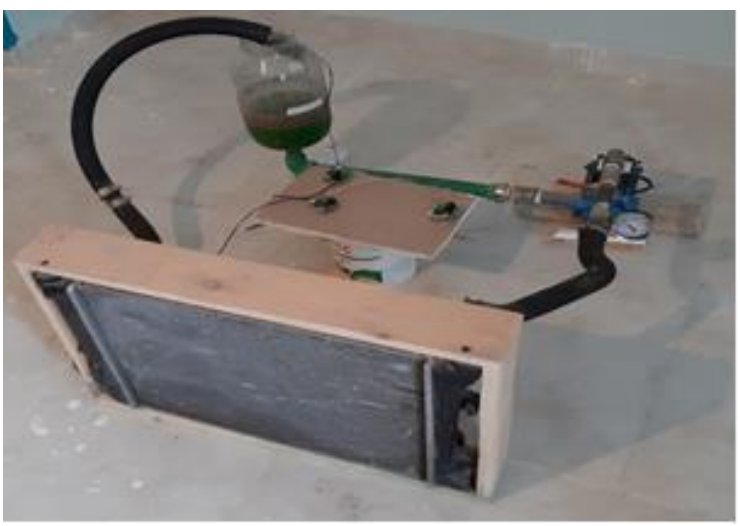

Figure 2 Model of car cooling system.

\section{Results and discussions}

This chapter contains the final results of the preparation of the Nano-Particles and the experimental work of this project with different coolants like water, Ethylene Glycol, Cu Nano-Fluid with different concentrations and $\mathrm{CuO}$ Nano-Fluid also with different concentrations and how it affects the characteristics of the heat transfer.

\section{Results of Nano-Particles}

\section{SEM}

SEM images show size and shape of cu NanoParticles is $30.47 \mathrm{~nm}$, round shape slightly to be spherical shape which is completely consistent with the estimate based on Sherrer's formula from the Xray line widths that. And copper oxide is $38.5 \mathrm{~nm}$ round shape less slightly to be spherical shape as shown in figures 3,4 TEM

Tem image explain crystalline structure of copper Nano-Particles and distance between two neighboring particles and that distance is $0.25 \mathrm{~nm}$ for copper\&0.28 $\mathrm{nm}$ for copper oxide and that mean there is high attractive forces between particles and that will be sign as Nano-Fluid of copper and copper oxide will be stable and homogeneous as shown in figures 5,6.

Zeta-Sizer

Zeta sizer test shows the size of the particles, it shows that size of $\mathrm{Cu}$ is $30.47 \mathrm{~nm}$ and size of $\mathrm{CuO}$ is that 38.5 as shown in figures 7,8 .

\section{Results of experimental work}

After doing a lot of experiments there are many variables that changes the exit temperature and the amount of heat rejects from the radiator like the surrounding temperature, type of coolant, size of radiator and fan, pump characteristics and flow speed.

\section{Effect of inlet temperature on exit temperature of the} radiator

Summer

Coolant $+\mathrm{Cu} 2 \%$ Vol. gives the highest temperature difference, water and Coolant + Cu $4 \%$ Vol are the lowest at condition of summer.

Difference between concentrations (" $\mathrm{Cu} 2 \%$ and $\mathrm{Cu} 1 \%$ " or "CuO $2 \%$ and $\mathrm{CuO} 1 \%$ ") at low temperature is lower than difference at high temperature and it due to low temperature difference between radiator exit and inlet as shown in figures 9,10.

Winter

Coolant $+\mathrm{Cu} 2 \%$ Vol gives the highest temperature difference, water, and Coolant $+\mathrm{Cu} 4 \% \mathrm{Vol}$ are the lowest. Difference between concentrations (" $\mathrm{Cu} 2 \%$ and $\mathrm{Cu} 1 \%$ " or "CuO $2 \%$ and $\mathrm{CuO} 1 \%$ ") at low temperature is lower than difference at high temperature and due to low temperature difference between radiator exit and inlet as shown in figures 11,12 . 


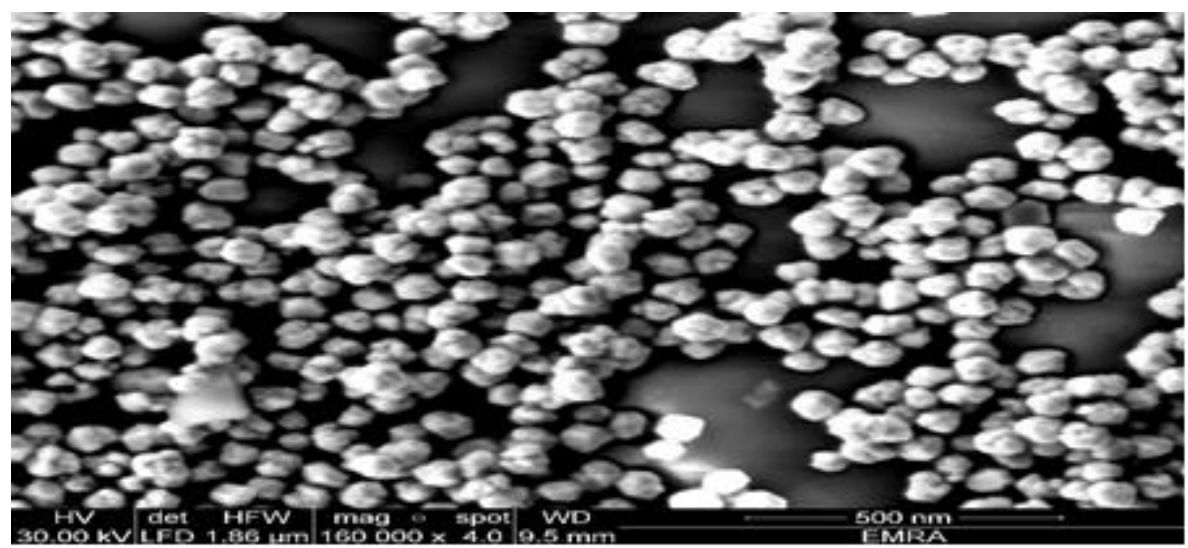

Effect of mass flow rate on exit temperature Summer

The lowest exit temperature is at Coolant $+\mathrm{Cu} 2 \%$ and Coolant + $\mathrm{CuO} 2 \%$ and it increase with increase in mass flow rate which means decrease in temperature difference between inlet and exit temperature.

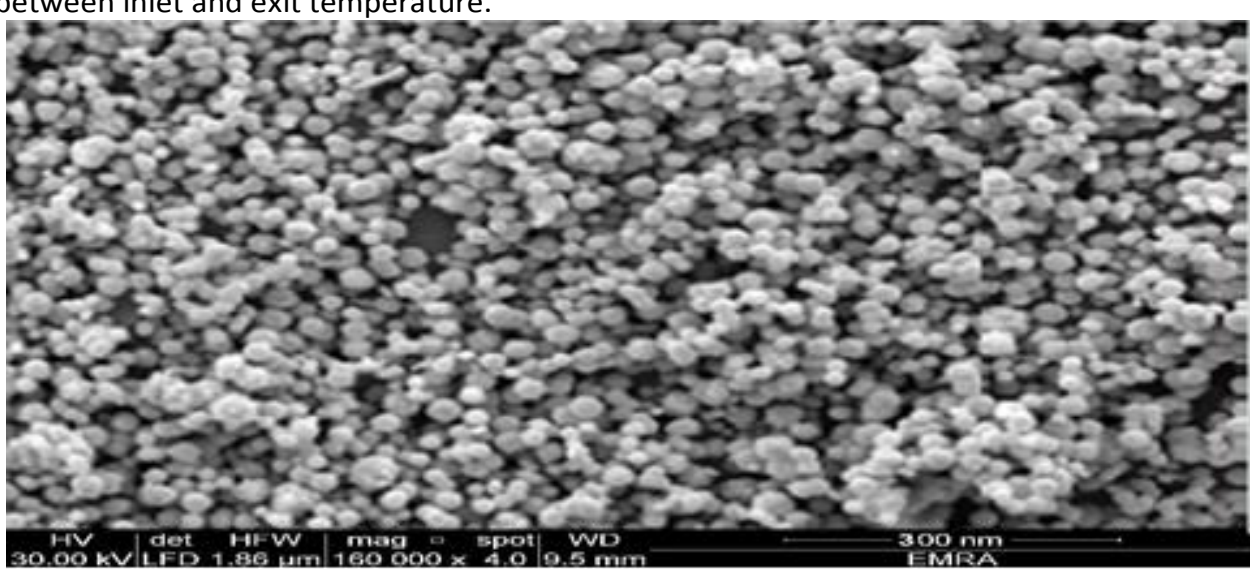

Figure 4 SEM of Cuo.

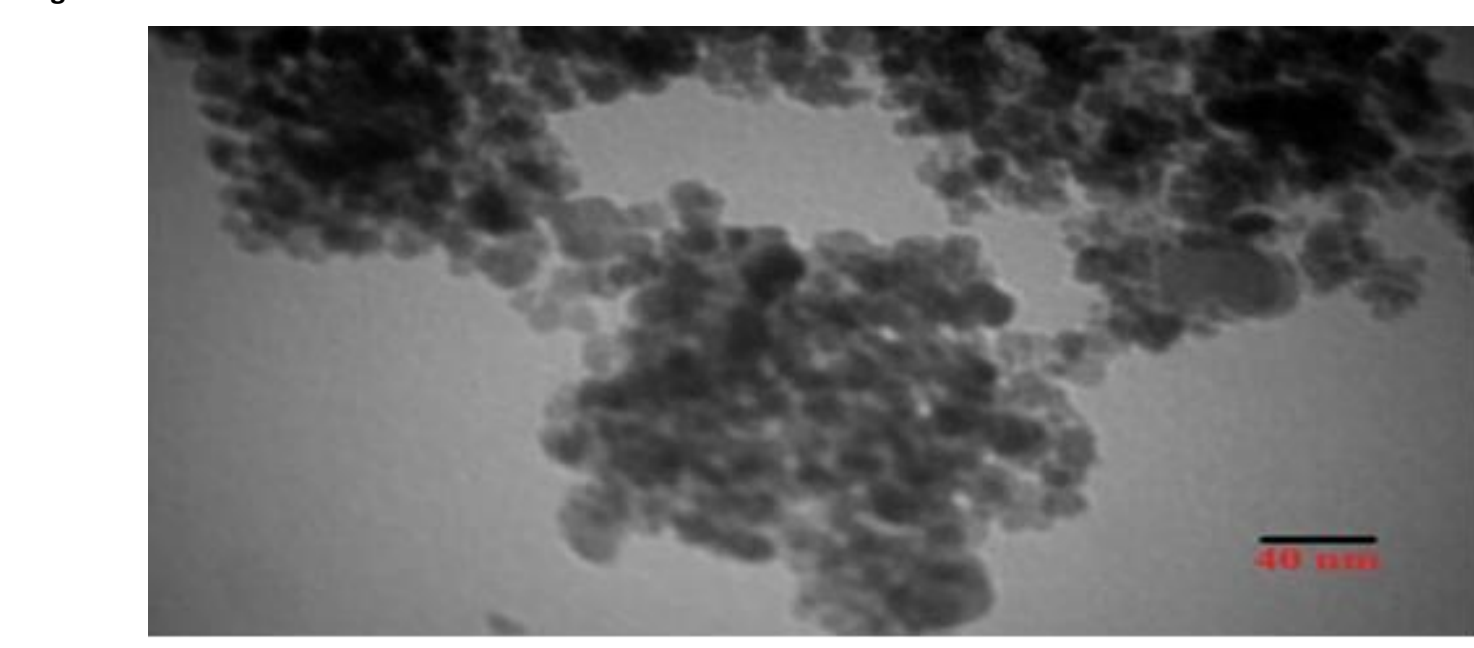

Figure 5 TEM of $\mathrm{Cu}$.
Water and Coolant $+\mathrm{Cu} 4 \%$ is the greatest exit temperature at most of cases but at high temperature inlet coolant are greater than Coolant $+\mathrm{Cu} 4 \%$ as shown in figures 13,14 . Figure 3 SEM of $\mathrm{Cu}$. 


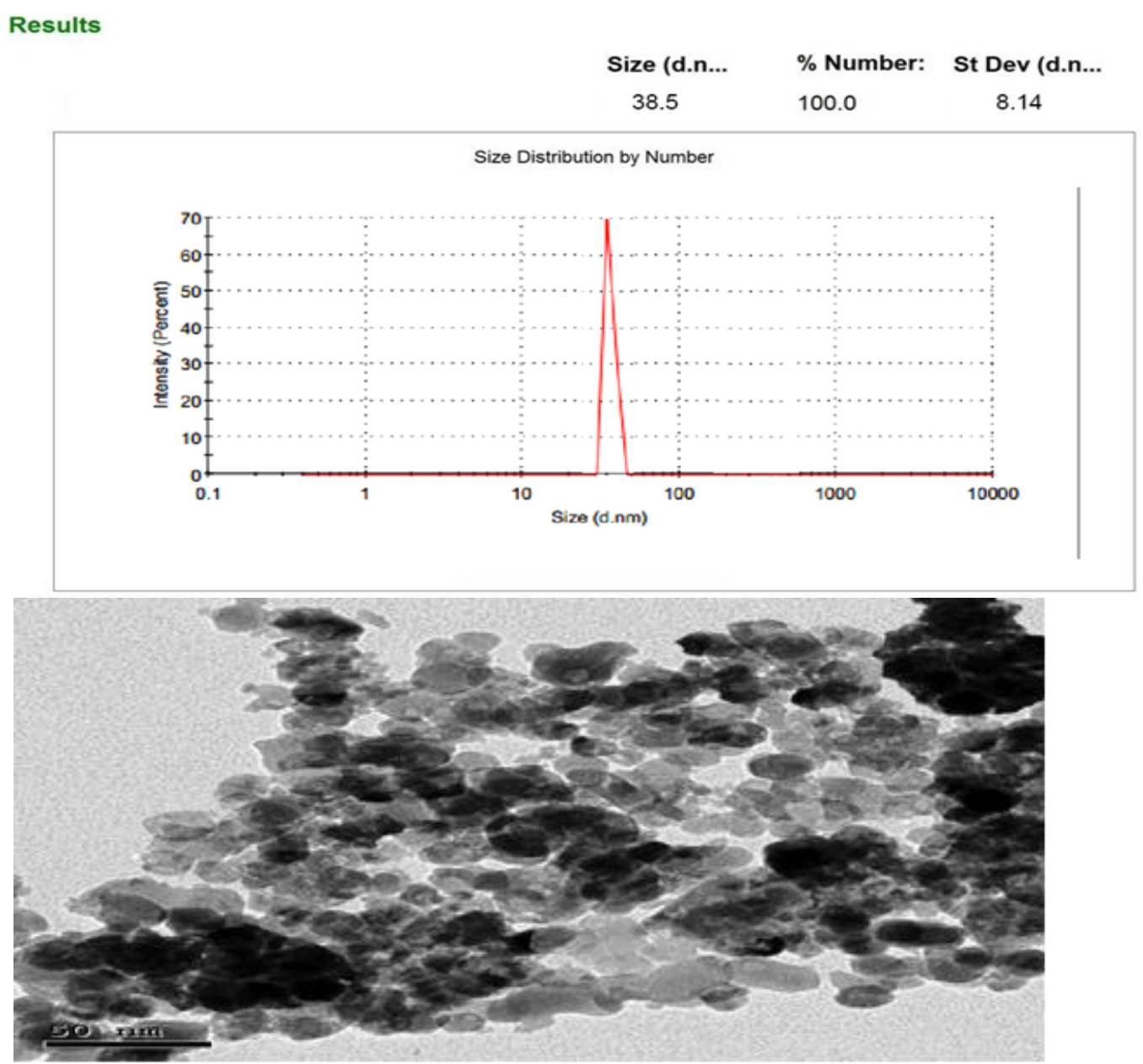

Figure 6 TEM of $\mathrm{CUO}$.

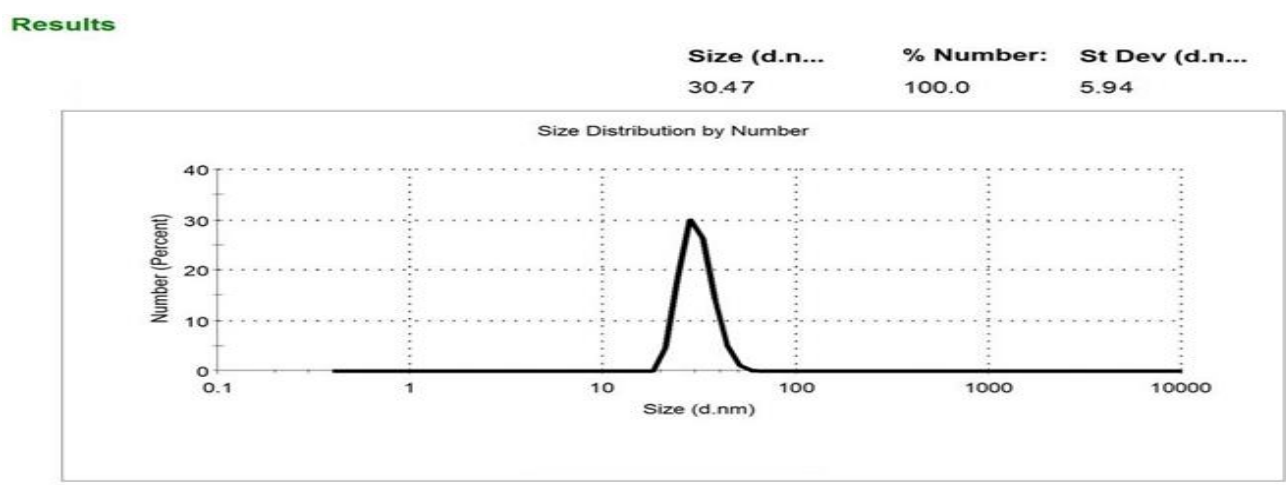

Figure 7 Zeta Sizer of Cu. 
Figure 8 Zeta Sizer of Cuo

Figure 9 Inlet temperature Vs exit temperature of the radiaton @ summer at 30o valve open.

of heat rejected with decrease in flow rate at different temperatures this is due to high difference in temperature between inlet and exit of radiator which got a big change in specific heat.

Coolant $+\mathrm{Cu} 4 \% \mathrm{Vol}$ in high difference in temperature between inlet and exit of radiator gives results close to Coolant $+\mathrm{CuO} 1 \%$ at high and medium flow rate and radiator gives results close to water at low flow rate as shown in figures 15,16. Winter

The lowest exit temperature is at Coolant $+\mathrm{Cu} 2 \%$ and Coolant $+\mathrm{CuO} 2 \%$ and it increase with increase in mass flow rate which means decrease in temperature difference between inlet and exit temperature.

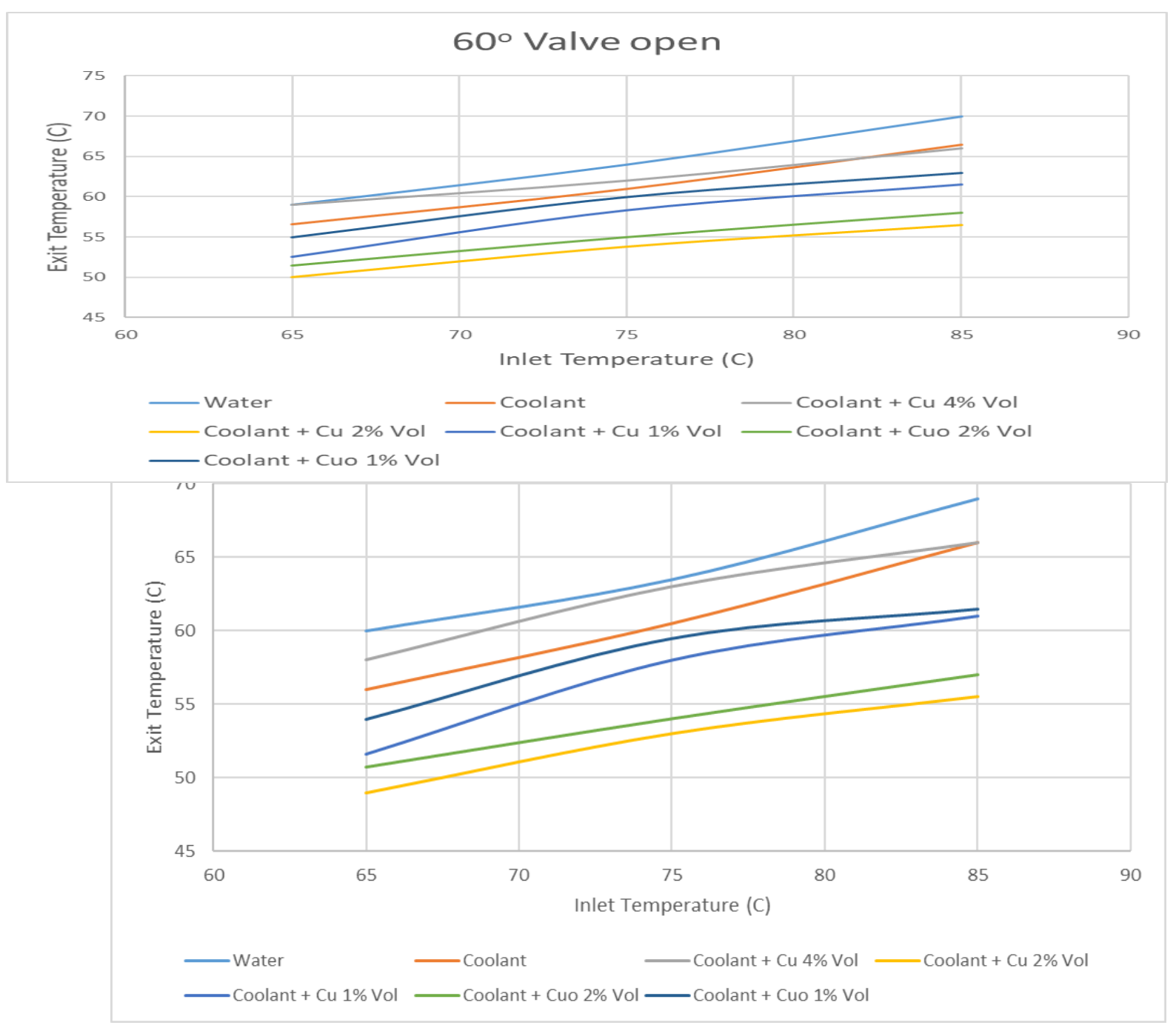


Figure 10 Inlet temperature Vs exit temperature of the radiator @ summer at 60o valve open.

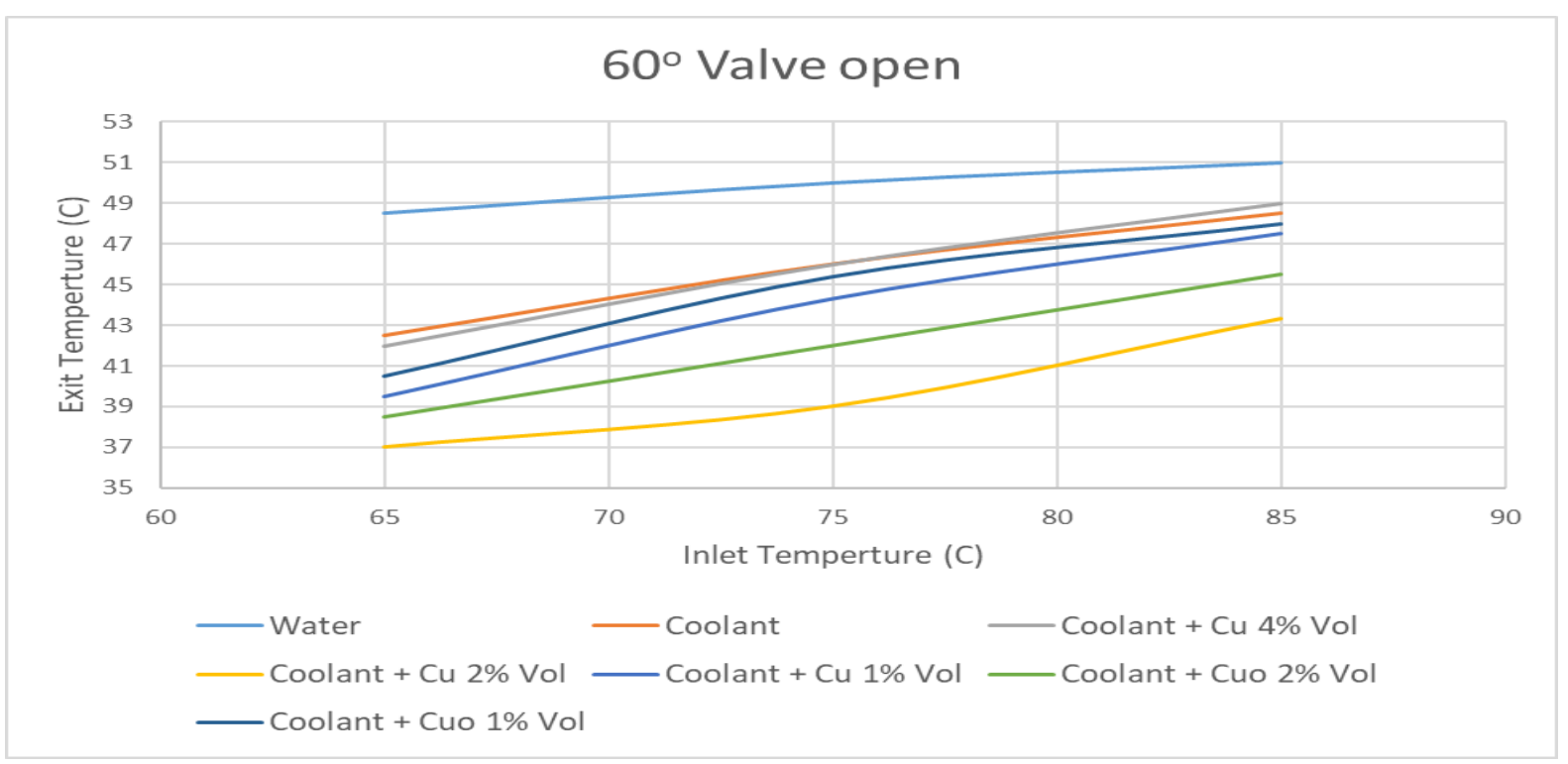

Figure 11 Inlet temperature Vs exit temperature of the radiator @ winter at 60o valve open.

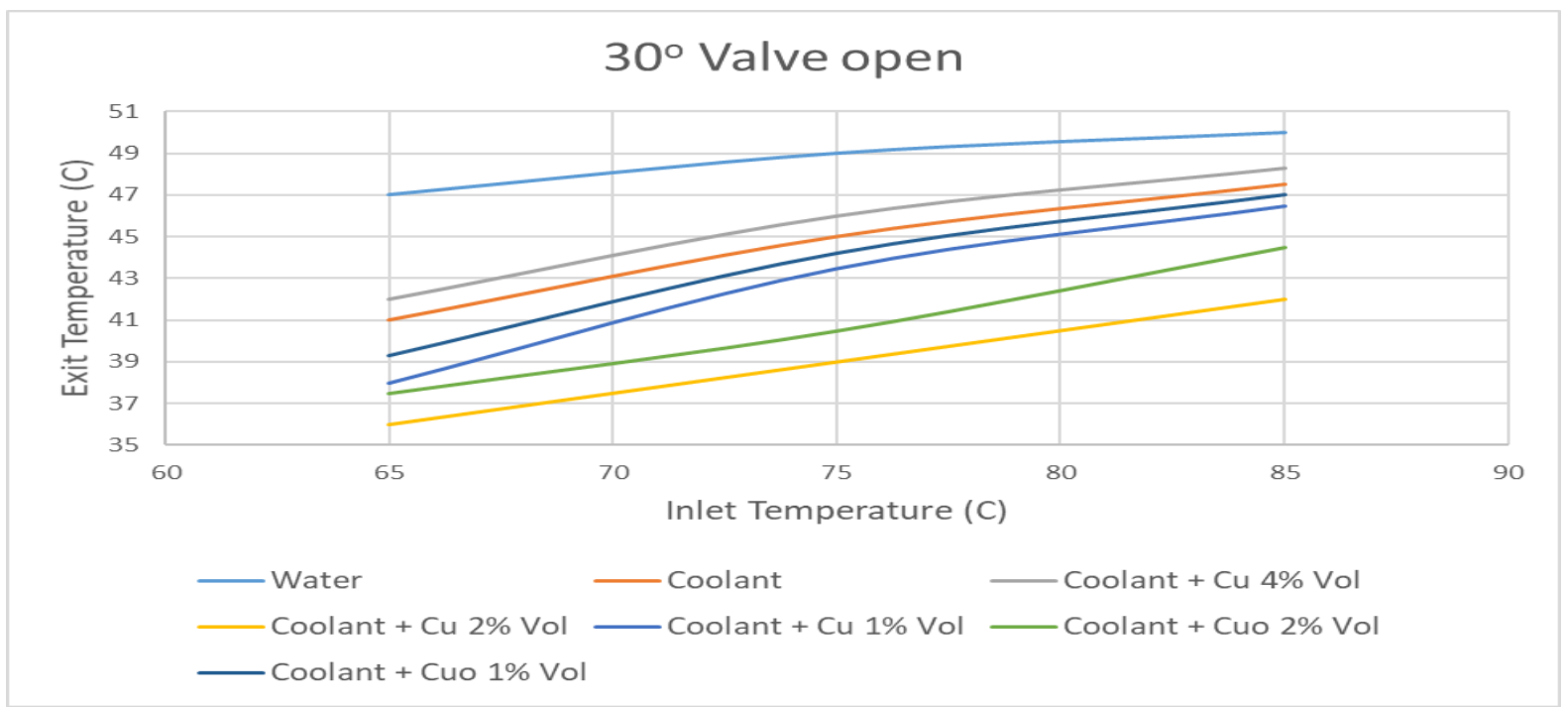

Figure 12 Inlet temperature Vs exit temperature of the radiator @ winter at 30o valve open. 


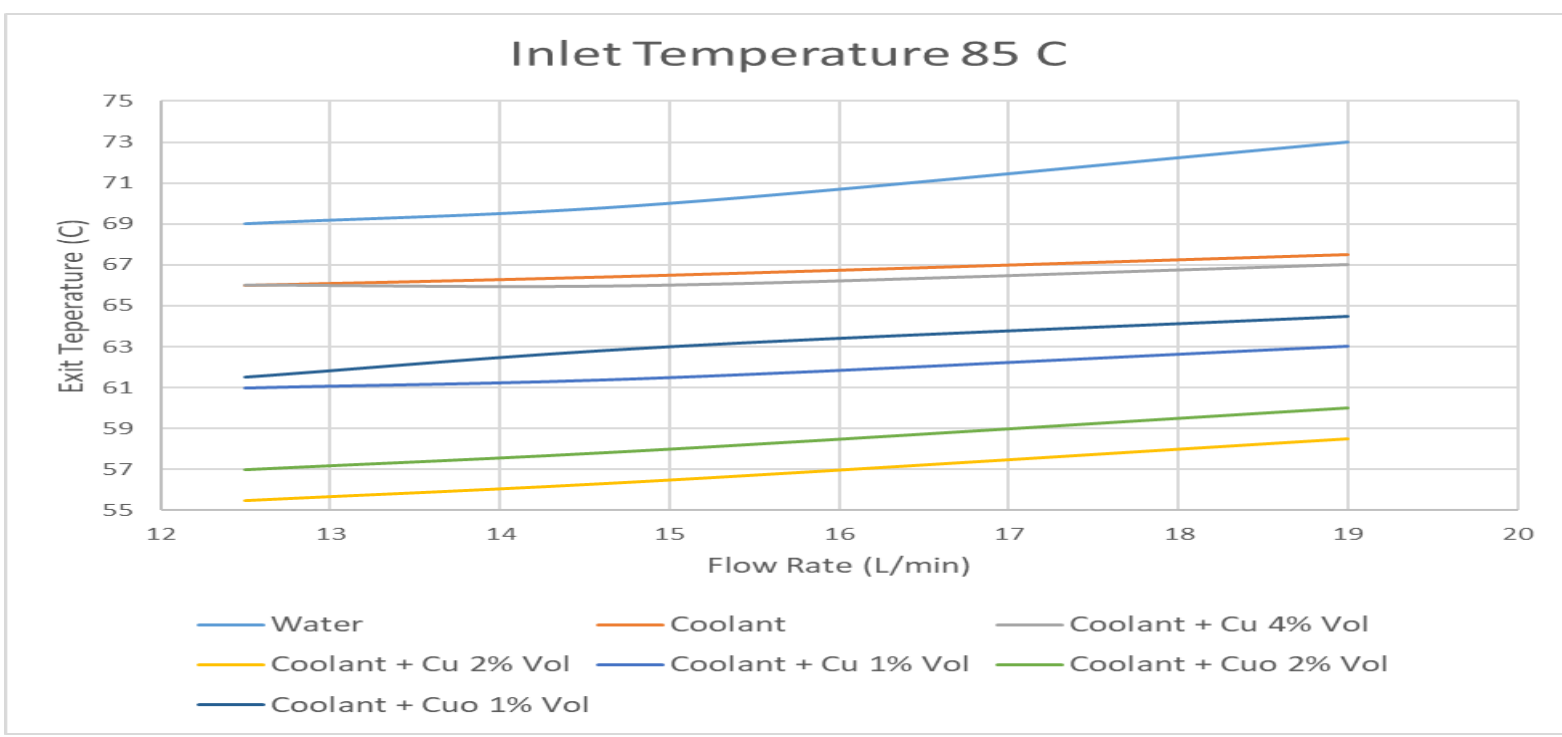

Figure 13 Mass flow rate Vs exit temperature with inlet temperature 85 oC @ summer.

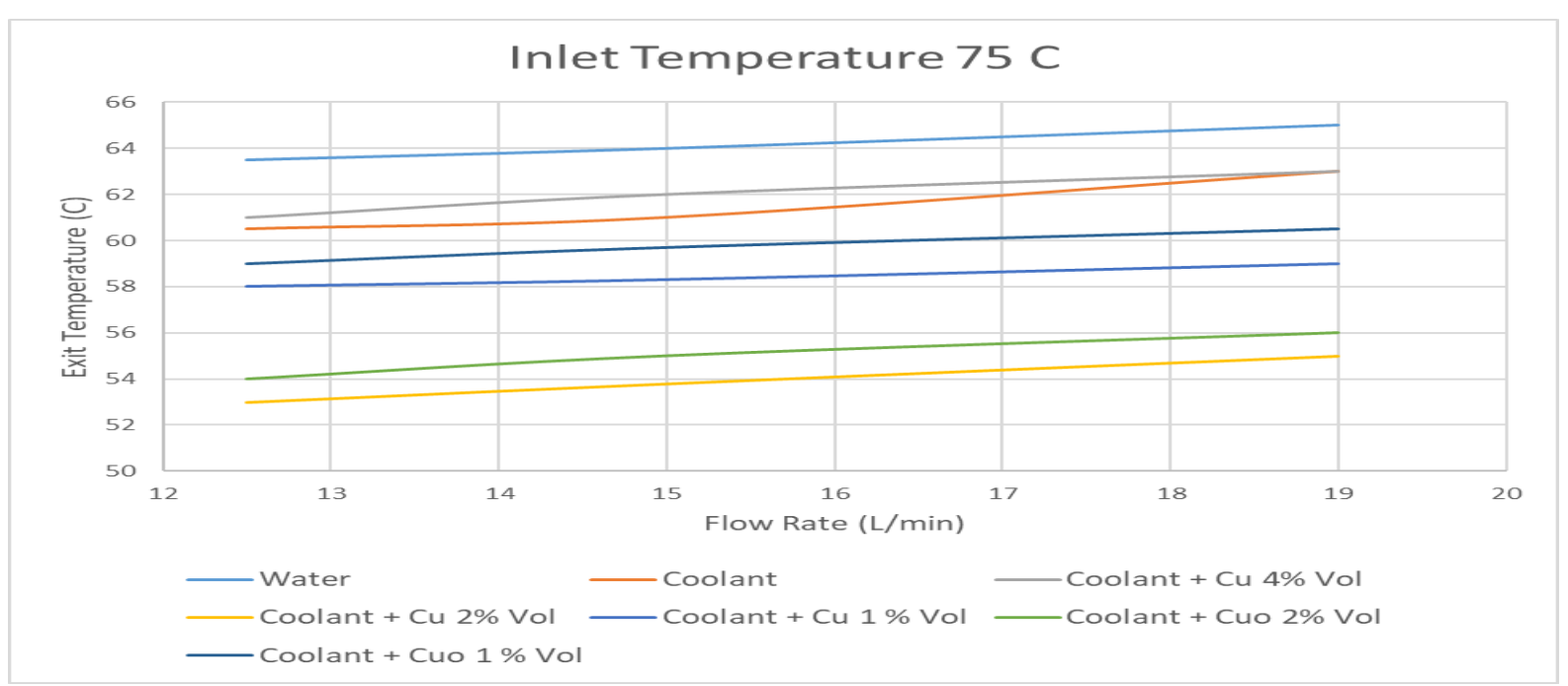

Figure 14 Mass flow rate Vs exit temperature with inlet temperature 75 oC @ summer.

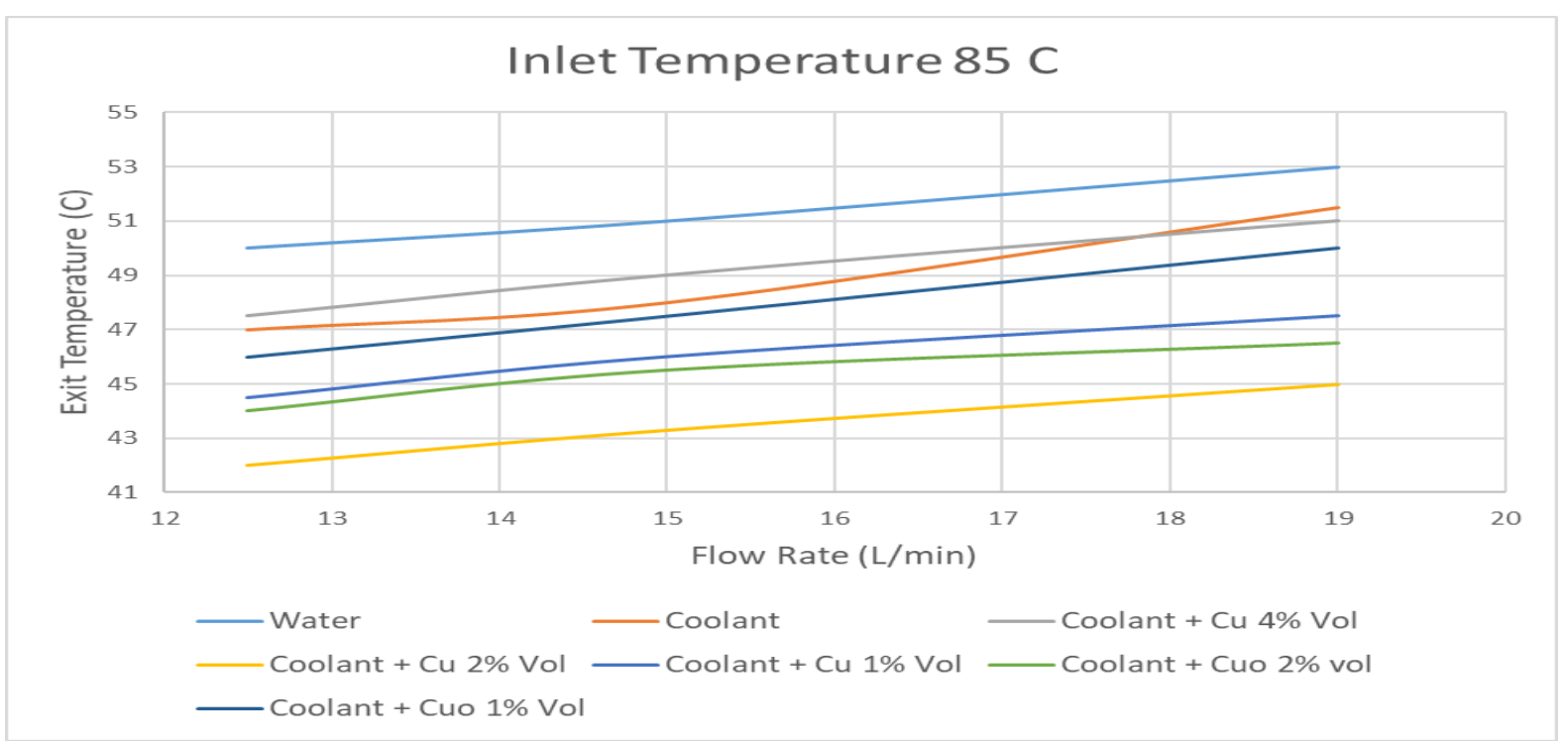

Figure 15 Mass flow rate Vs exit temperature with inlet temperature 85 oC @ winter. 


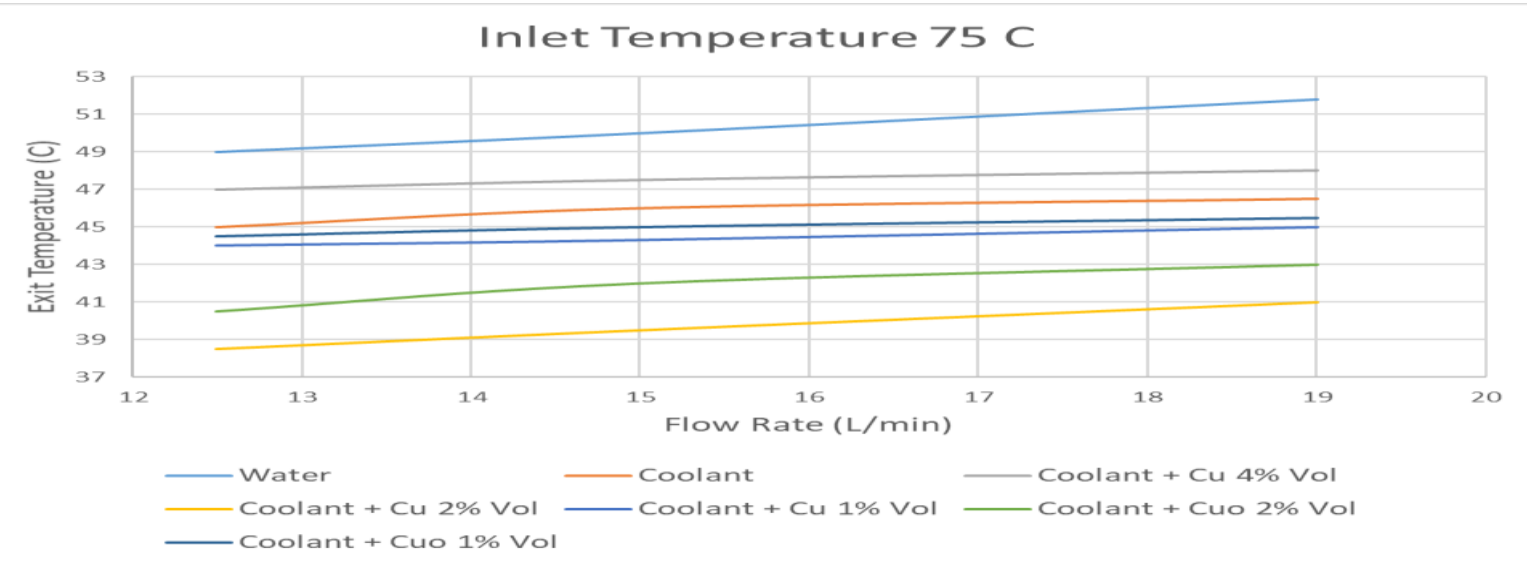

Figure 16 Mass flow rate Vs exit temperature with inlet temperature 75 oC @ winter.

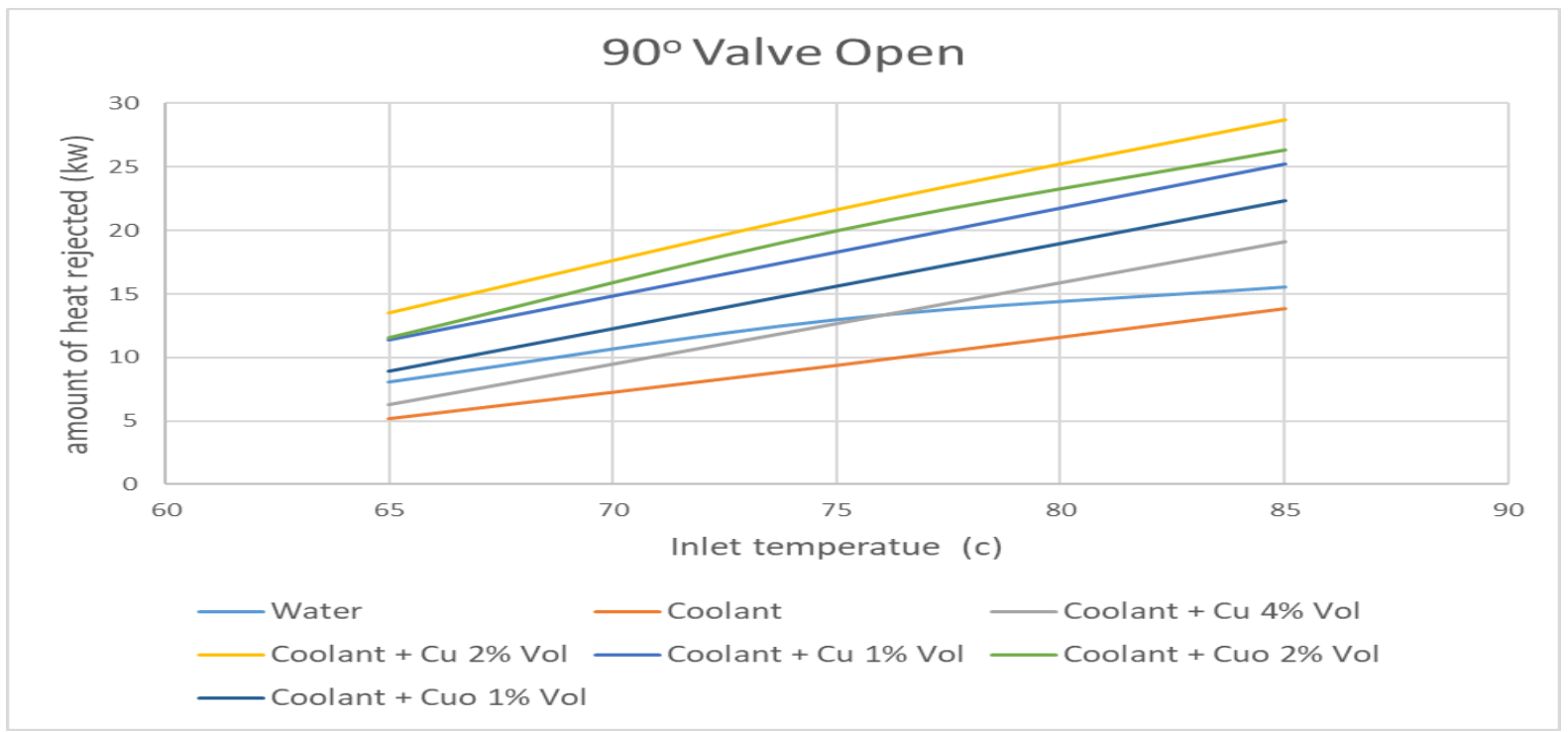

Figure 17 Inlet temperature Vs amount of heat rejected @ summer at 90o valve open.

low flow rates coolant will be better due to big deviation in density and specific heat of coolant and water as shown in figures 17,18 .

Water and Coolant $+\mathrm{Cu} 4 \%$ is the greatest exit temperature at most of cases but at high temperature and high flow rate inlet coolant are greater than Coolant $+\mathrm{Cu} 4 \%$ as shown in figures 15,16 .

\section{Effect of inlet temperature on amount of heat rejected Summer}

Relation between inlet temperature of radiator and amount of heat rejected in different flow rates, Coolant $+\mathrm{Cu} 2 \% \mathrm{Vol}$ is better due to, it has the greatest amount of heat rejected than Coolant $+\mathrm{CuO}$ $2 \%$ Vol. At high flow rate water is better than coolant due to small deviation in density and specific heat but at

\section{Winter}

Coolant $+\mathrm{Cu} 2 \% \mathrm{Vol}$ is greatest amount of heat rejected and Coolant increase amount of heat rejected with decrease in flow rate at different temperatures this is due to high difference in temperature between inlet and exit of radiator which got a big change in specific heat.

Coolant $+\mathrm{Cu} 4 \% \mathrm{Vol}$ in high difference in temperature between inlet and exit of radiator gives results close to Coolant $+\mathrm{CuO} 1 \%$ at high and medium flow rate and radiator gives results close to water at low flow rate as shown in figures 5-17,18.

\section{Conclusions}

- Nano-particles when introduced to a conventional fluid in certain concentrations they enhance the ability to transfer heat, has the benefits of lower energy costs and the environmental impact.

- Nano-particles additives have the benefits of minimization the energy cost and much better environmental impact.

- Difference between concentrations (" $\mathrm{Cu} 2 \%$ and $\mathrm{Cu}$ $1 \%$ " or "CuO $2 \%$ and $\mathrm{CuO} 1 \%$ ") at low temperature is lower than difference at high temperature and it due to low temperature difference between radiator exit and inlet.

- Water and Coolant $+\mathrm{Cu} 4 \%$ is the greatest exit temperature at most of cases but at high temperature and high flow rate inlet coolant are greater than Coolant $+\mathrm{Cu} 4 \%$.

- At high flow rate water is better than coolant due to small deviation in density and specific heat but at low flow rates coolant will be better due to big deviation in density and specific heat of coolant and water. 


\section{$30^{\circ}$ Valve Open}

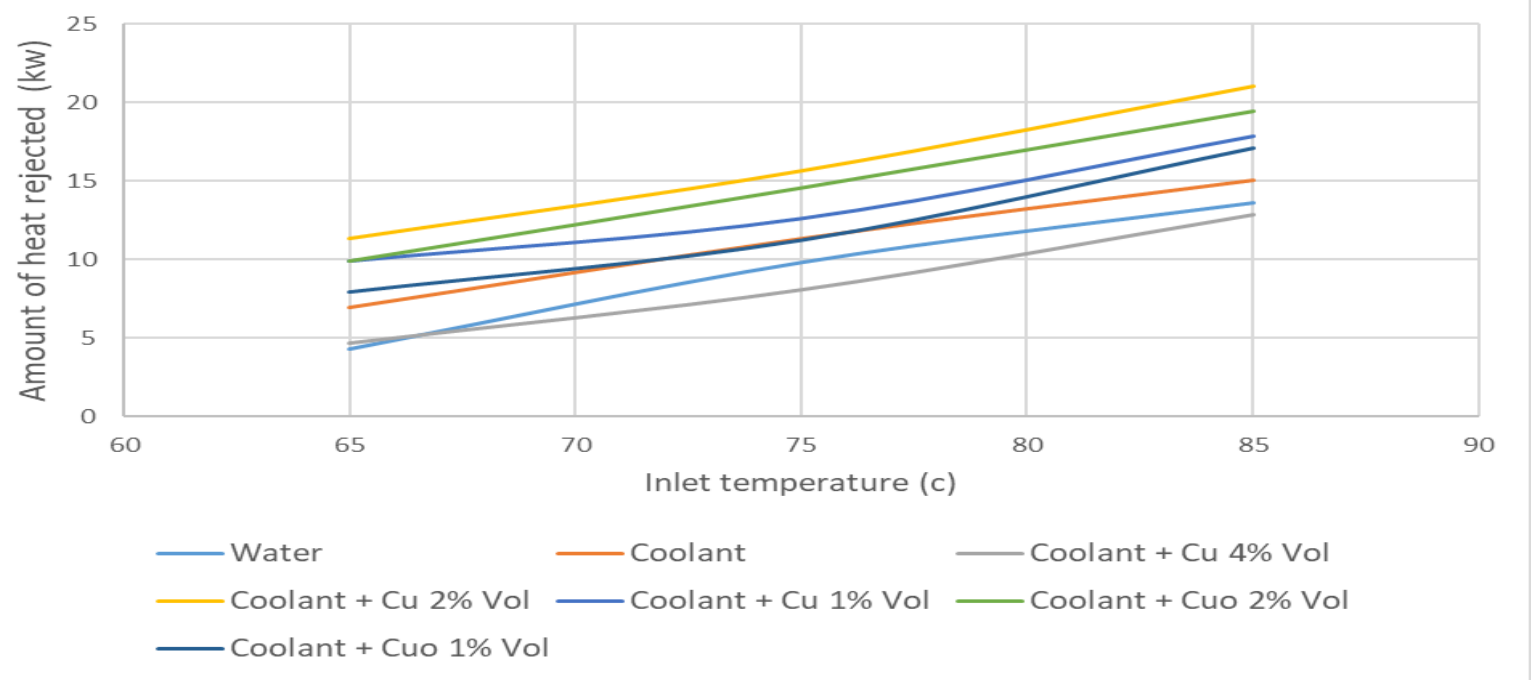

Figure 18 Inlet temperature Vs amount of heat rejected @ summer at 30o valve open.

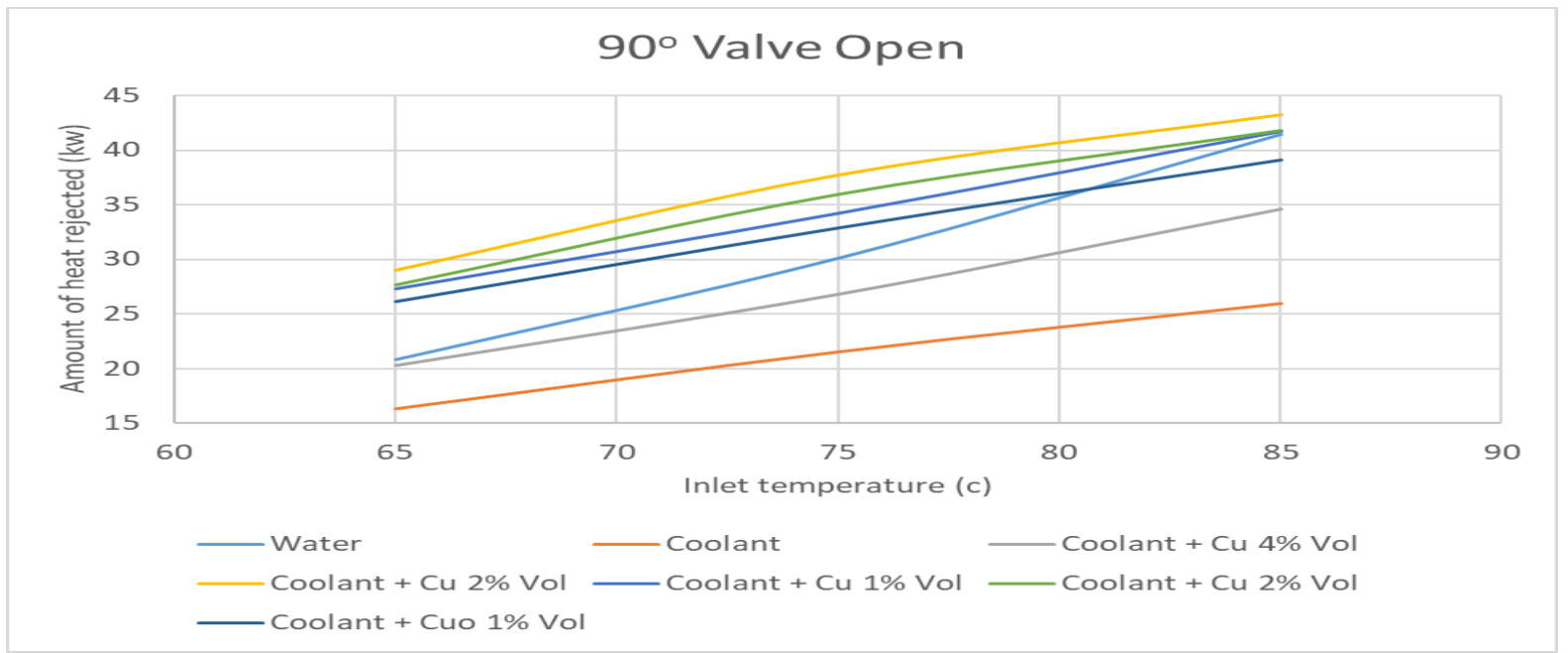

Figure 19 Inlet temperature Vs amount of heat rejected @ winter at 90o valve open.

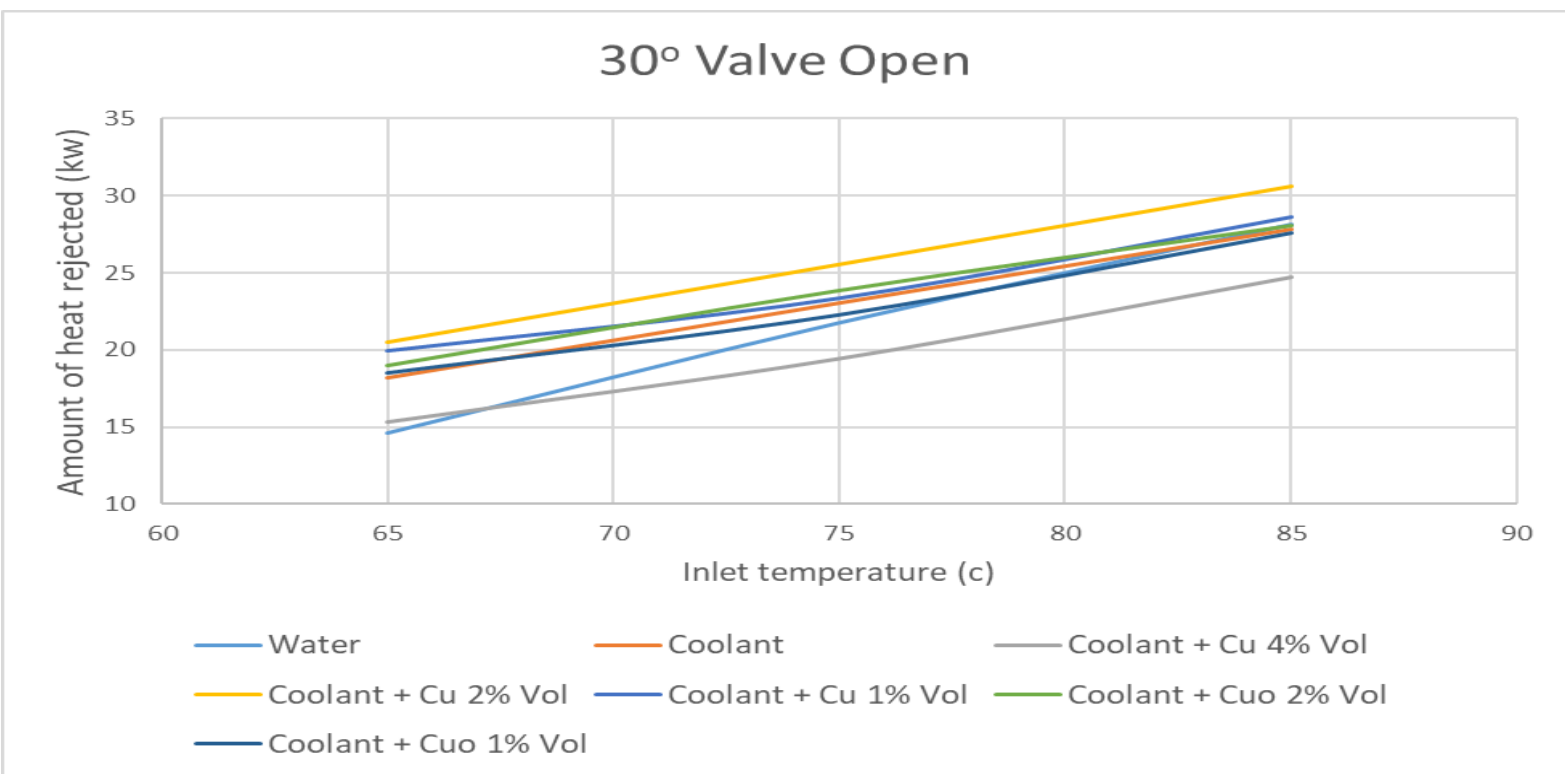

Figure 20 Inlet temperature Vs amount of heat rejected @ winter at 30o valve open. 
- Coolant $+\mathrm{Cu} 4 \% \mathrm{Vol}$ in high difference in temperature between inlet and exit of radiator gives results close to Coolant $+\mathrm{CuO} 1 \%$ at high and medium flow rate and radiator gives results close to water at low flow rate.

- This enhancement leads to reduce the radiator frontal area which results in reducing the frontal area of the vehicle that leads to lower the coefficient of drag (resistance of the air for the moving vehicle) consequently reduces the fuel consumption.

\section{References}

[1] Nanaware M.H , Hole J.A, Review Paper on Radiators By Using Different Nano-Fluid, IOSR Journal of Mechanical and Civil Engineering (IOSR-JMCE),2018,3.

[2] Mohammed Saad Kamel, Raheem Abed Syeal, Ayad Abdulameer Abdulhussein, Heat Transfer Enhancement Using Nano-Fluids: A Review of the Recent Literature, American Journal of Nano Research and Applications, 2016; 4(1),5.

[3] Kambiz Vafai, Khalil Khanafer, A critical synthesis of thermos-physical characteristics of Nano-Fluids, International Journal of Heat and Mass Transfer, 2015,20.

[4] M. M. Ghosh, S. Ghosh, S. K. Pabi, A Parameter for Selection of Nano-dispersions in Nano-Fluids for Thermal Applications, Materials Science Forum, 736 , 2013 ,7.

[5] Alpesh Mehta, Dinesh k Tantia, Nilesh M Jha , Nimit M Patel, HEAT EXCHANGER USING NANO FLUID, International Journal of Advanced Engineering Technology, 976, 2012, 6.

[6] A.R. Solankee, Prof.S.R. Kulkarni, Industrial Applications of Nano Fluids: A Review, IJSRD - International Journal for Scientific Research \& Development, 4, 2016, 5.

[7] Elumagandla Surendar, Poreddy Prashanth, Snaga Sarada, effect of Nano-Fluid on heat transfer characteristics of shell and tube heat exchangers: effect of Alunimium oxide NANO-FLUID, International Research Journal of Engineering and Technology (IRJET), 2, 2015, 19.

[8] Kaufui V.Wong, Michael J. Castillo, Heat Transfer Mechanisms and Clustering in Nano-Fluids, Hindawi Publishing Corporation Advances in Mechanical Engineering , 2010,9.

[9] Ramin Ranjbarzadeh , Alireza Moradi Kazerouni , Reza Bakhtiari , Amin Asadi, Masoud Afrand, An experimental study on stability and thermal conductivity of water/silica Nano-Fluid: eco-friendly production of Nano-Particles, Journal of Cleaner Production, 206 , 2018 , 1089-1100.

[10] Wei Yu, Huaqing Xie, A Review on Nano-Fluids: Preparation, Stability Mechanisms and Applications, Journal of Nanomaterials, 2012, 2012, 17.

[11] Roshan V. Marode, Somesh Santosh Junare, Umesh Haribhau Kamble, A Review on Performance of Heat Exchanger using Nano-Fluids, 2nd National Conference Recent Innovations in Science and Engineering (NC-RISE 17), 5, 2017, 63-66.

[12] Hanif, Gaurav Saxena, Janmit Raj, A Critical Review on Applications of Nano-Fluid as Coolant, International
Journal of Engineering and Management Research, 7, 2017, 304-311. 